Keywords: $M C U, A R P, I S D P$, SWPF

Retention: Permanent

\title{
Results of Analyses of the Next Generation Solvent for Parsons
}

T. B. Peters

A. L. Washington, II

S. D. Fink

February 2012

Savannah River National Laboratory Savannah River Nuclear Solutions

Aiken, SC 29808

Prepared for the U.S. Department of Energy under

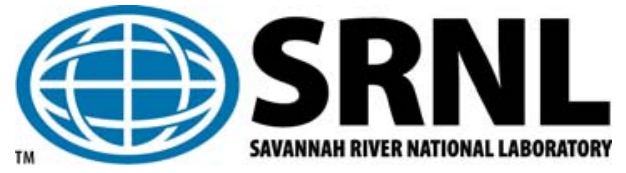
contract number DE-AC09-08SR22470. 
SRNL-STI-2012-00065

Revision 0

\section{DISCLAIMER}

This work was prepared under an agreement with and funded by the U.S. Government. Neither the U.S. Government or its employees, nor any of its contractors, subcontractors or their employees, makes any express or implied:

1. warranty or assumes any legal liability for the accuracy, completeness, or for the use or results of such use of any information, product, or process disclosed; or

2. representation that such use or results of such use would not infringe privately owned rights; or

3. endorsement or recommendation of any specifically identified commercial product, process, or service.

Any views and opinions of authors expressed in this work do not necessarily state or reflect those of the United States Government, or its contractors, or subcontractors.

Printed in the United States of America

Prepared for

U.S. Department of Energy 


\section{REVIEWS AND APPROVALS}

\section{AUTHORS:}

T. B. Peters, Author, SRNL/SASP

Date

A. L. Washington, II, co-author, SRNL/SASP

Date

TECHNICAL REVIEW:

C. A. Nash, Technical Reviewer, SRNL/ACP

Date

\section{APPROVAL:}

S. D. Fink, SRNL/SASP, Manager

Date

S. L. Marra, SRNL/E\&CPT Research Programs, Manager

Date

S. G. Campbell, SRR Engineering Technical Integration

Date

P. C. Suggs, DOE Waste Disposition Programs Division

Date 


\section{EXECUTIVE SUMMARY}

Savannah River National Laboratory (SRNL) prepared a nominal 150 gallon batch of Next Generation Solvent (NGS) for Parsons. This material was then analyzed and tested for cesium mass transfer efficiency. The bulk of the results indicate that the solvent is qualified as acceptable for use in the upcoming pilot-scale testing at Parsons Technology Center. 


\title{
LIST OF ABBREVIATIONS
}

\author{
AD - Analytical Development \\ EDL - Engineering Development Laboratory \\ ESS - Extraction, Scrub, Strip \\ FTIR - Fourier Transform Infrared Spectroscopy \\ HPLC - High Performance Liquid Chromatography \\ NGS - Next Generation Solvent \\ RSD - relative standard deviation \\ SRNL - Savannah River National Laboratory \\ SVOA - Semi Volatile Organic Analysis
}




\subsection{Introduction}

This report describes the analysis and testing of a batch of Next Generation Solvent (NGS) prepared in support of pilot-scale testing in the Parsons Technology Center. ${ }^{1}$ A total of 150 gallons of NGS solvent was prepared in late November of 2011. Details for the work are contained in a controlled laboratory notebook. ${ }^{2}$

\subsection{Experimental Procedure}

In late November 2011, the Engineering Development Laboratory (EDL) prepared 150 gallons of NGS solvent and contained the material in three stainless steel drums. Two samples from each drum were removed and archived, generating six samples in total. 10 $\mathrm{mL}$ from each archived sample were combined into a single bottle and mixed to generate a solvent composite. The three drums were shipped to Parsons Technology Center on 5 December 2011 along with $\sim 270 \mathrm{lb}$ of Isopar $^{\circledR} \mathrm{L}, \sim 70 \mathrm{lb}$ of Modifier, $\sim 1 \mathrm{~kg}$ of a guanidine derivative, and the unused portion of the MaxCalix extractant.

This composite sample from the three drums was then analyzed via Semi-Volatile Organic Analysis (SVOA), High Performance Liquid Chromatography (HPLC), Fourier Transform Infra-Red (FTIR) spectroscopy and tested for cesium mass transfer efficiency in an Extraction-Scrub-Strip (ESS) test.

\subsection{Results and Discussion}

Three, 50 gallon batches of the NGS solvent was prepared in three different clean, stainless steel drums (\#1, \#3 and \#5). The same procedure was used used to mix the components in each drum. ${ }^{3}$ First, half the required weight of Isopar ${ }^{\circledR} \mathrm{L}$ was added, followed by the entire weight of the Modifier. ${ }^{\vee}$ Then, the entire weight of the guanidine ${ }^{\Upsilon}$ was added, followed by the entire weight of the MAXCalix." Finally, the remainder of the Isopar ${ }^{\circledR} \mathrm{L}$ was added. The contents of the drum were then mixed for $\sim 1$ hour. There was no active temperature control, and the activity took place at room temperature ( 20$22{ }^{\circ} \mathrm{C}$ ). The masses of each material were recorded in each addition. Mixing was provided by an overhead mixer inserted into the drum. Table 1 lists the weights of each component used in each drum in kilograms.

\section{Table 1. Weights of Components in Each Drum (kg)}

\begin{tabular}{|c|c|c|c|}
\hline Component & Drum \#1 & Drum \#3 & Drum \#5 \\
\hline Isopar $^{\circledR} \mathrm{L}$ & 119 & 119 & 119 \\
\hline Modifier & 32.2 & 32.1 & 32.2 \\
\hline MAXCalix & 9.08 & 9.08 & 9.08 \\
\hline Guanidine & 0.230 & 0.230 & 0.230 \\
\hline
\end{tabular}

${ }^{\checkmark}$ Modifier stands for_1-(2,2,3,3,-Tetrafluoropropoxy)-3-(4-sec-butylphenoxy)-2-propanol

$\Upsilon$ "guanidine", the suppressor, is short for $\mathrm{N}, \mathrm{N}$ '-cyclohexyl, $\mathrm{N}$ "'-isotridecyl guanidine

- The extractant, MaxCalix, stands for 1,3-alt-25,27-Bis(3,7-dimethyloctyloxy)calix[4]arenebenzocrown-6 
Two, $30 \mathrm{~mL}$ samples from the contents of each prepared drum were removed. From each of these six samples, SRNL removed $10 \mathrm{~mL}$ of sample and composited these into a single Teflon ${ }^{\mathrm{TM}}$ bottle. The density of the solvent composite was measured once using a $2 \mathrm{~mL}$ density tube, and three times using a $10 \mathrm{~mL}$ electronic pipette. The average of these measurements gave a density of $0.845 \mathrm{~g} / \mathrm{mL}$ with a residual standard deviation (RSD) of $0.25 \%\left(\mathrm{~T}=25^{\circ} \mathrm{C}\right)$. This result is higher than what is predicted to be the correct density $\left(0.827-0.839 \mathrm{~g} / \mathrm{mL}\right.$ at $\left.25^{\circ} \mathrm{C}\right) .{ }^{4,5} \mathrm{SRNL}$ re-measured the solvent in triplicate, using only $2 \mathrm{~mL}$ density tubes, and taking care to minimize reading errors. In this re-measurement, the density was measured to be $0.828 \mathrm{~g} / \mathrm{mL}$ with a RSD of $0.16 \%\left(\mathrm{~T}=21.5^{\circ} \mathrm{C}\right)$. SRNL feels that this second set of measurements is more accurate. We have found that with lighter density organic materials, using $10 \mathrm{~mL}$ pipettes to measure the density is problematic. We recommend preferentially using the $2 \mathrm{~mL}$ glass tubes in the future.

Given the very small difference between the target and measured density, SRNL does not recommend trying to trim the solvent.

After the density measurement, samples of the composite were analyzed by SVOA, HPLC, and FTIR. The results are reported in Table 2.

The analytical results are consistent with each other. The Isopar ${ }^{\circledR} \mathrm{L}$ concentration appears slightly low, with the Modifier slightly high and the Extractant concentration on target. The HPLC and FTIR data suggests very little variance from the nominal results while SVOA data shows a greater variance. Historically, SVOA tends to not agree as well as the other two methods. However, these results are all within the analytical method uncertainties of being on target (100\%).

The guanidine analysis concentration appears low. However, while the SVOA analysis is derived from ORNL protocols, ${ }^{6}$ the equivalent SRNL method has not been rigorously developed for this compound and preference is given to the gravimetric data from preparations. Analytical Development (AD) is still qualifying the analytical method for this analyte. The calibration curves for this analysis are not within acceptable parameters at this point. Therefore, this low result compared to nominal values should not be taken to mean the guanidine is low, but that the method is still being developed. (The ORNL equipment is a dedicated instrument for the research program; the SRNL instrument is used for multiple programs and routine analyses. Hence, less optimal performance for the SRNL equipment in not unexpected.). 
Table 2. Sample Results for the NGS Composite

\begin{tabular}{|c|c|c|c|c|c|}
\hline Analysis & Method & LIMS \# & $\begin{array}{l}\text { Result } \\
(\mathrm{mg} / \mathrm{L})^{\#}\end{array}$ & $\begin{array}{c}\text { Nominal } \\
\text { Result } \\
(\mathrm{mg} / \mathrm{L})\end{array}$ & $\begin{array}{c}\% \text { of (Result } \div \\
\text { Nominal Result) }\end{array}$ \\
\hline Isopar $^{\circledR} \mathrm{L}$ & SVOA & 300295789 & 570,000 & 629,000 & $90.6 \%$ \\
\hline Isopar $^{\circledR} \mathrm{L}$ & FTIR & NA & 610,000 & 629,000 & $97.0 \%$ \\
\hline average & all & NA & & & $93.8 \%$ \\
\hline Modifier & SVOA & 300295789 & 185,000 & 170,000 & $109 \%$ \\
\hline Modifier & HPLC & 300295789 & 179,000 & 170,000 & $105 \%$ \\
\hline Modifier & FTIR & NA & 165,000 & 170,000 & $97.1 \%$ \\
\hline average & all & NA & & & $104 \%$ \\
\hline guanidine & SVOA & 300295789 & 650 & 1,220 & $53.3 \%$ \\
\hline Extractant & HPLC & 300295789 & 46,000 & 47,900 & $96.0 \%$ \\
\hline Extractant & FTIR & NA & 49,300 & 47,900 & $103 \%$ \\
\hline average & All & NA & & & $99.5 \%$ \\
\hline
\end{tabular}

${ }^{\#}$ Analytical uncertainty is $20 \%$ for SVOA and $10 \%$ for HPLC. FTIR analytical uncertainty is $15 \%$ for Isopar ${ }^{\circledR}$ L, $10 \%$ for Modifier and $25 \%$ for Extractant. Density results from the average of replicate volumetric trials typically have a percentage standard deviation of $<1 \%$ between each value and the average.

$\mathrm{NA}=$ not applicable

\subsection{ESS Testing}

For the ESS tests, we followed the same protocol established for recent work. ${ }^{7,8}$ The ESS test is a series of organic (solvent) to aqueous (Tank $49 \mathrm{H}$ simulant) contacts. There are extraction step, two scrub steps, and three strip steps. Between each step we separate the phases, remove a portion of each phase for analysis, and place one of the phases back in the funnel and contact it with a new organic or aqueous phase (Table 3 ). The two phases are allowed to contact for $\sim 24$ hours before proceeding to the next step. 
Table 3. ESS Test Steps

\begin{tabular}{|c|c|c|c|c|}
\hline Step \# & Type & $\begin{array}{c}\text { Nominal } \\
\text { Volume } \\
\text { ORGANIC }\end{array}$ & $\begin{array}{c}\text { Nominal } \\
\text { Volume } \\
\text { AQUEOUS }\end{array}$ & $\begin{array}{c}\text { O/A } \\
\text { Ratio }\end{array}$ \\
\hline 1 & Extraction & $30 \mathrm{~mL}$ & $120 \mathrm{~mL}$ & 0.25 \\
\hline 2 & Scrub \#1 & $30 \mathrm{~mL}$ & $7.5 \mathrm{~mL}$ & 3.75 \\
\hline 3 & Scrub \#2 & $30 \mathrm{~mL}$ & $7.5 \mathrm{~mL}$ & 3.75 \\
\hline 4 & Strip \#1 & $30 \mathrm{~mL}$ & $7.5 \mathrm{~mL}$ & 3.75 \\
\hline 5 & Strip \#2 & $30 \mathrm{~mL}$ & $7.5 \mathrm{~mL}$ & 3.75 \\
\hline 6 & Strip \#3 & $30 \mathrm{~mL}$ & $7.5 \mathrm{~mL}$ & 3.75 \\
\hline
\end{tabular}

The original Cs-containing aqueous phase was a waste simulant spiked with ${ }^{137} \mathrm{Cs}$. The scrub aqueous phase is $0.025 \mathrm{M}$ sodium hydroxide, and the strip aqueous phase is 0.001 $\mathrm{M}$ boric acid.

The Cs content for each phase in each step is measured by gammascan with a typical 5\% analytical uncertainty. Once corrected for operating temperature ${ }^{9}$-- each step has its own temperature correction factor -- the distribution values are calculated. The distribution factor, $\mathrm{D}_{\mathrm{Cs}}$, for any particular step is equal to the Cs concentration in the organic phase divided by the Cs concentration in the aqueous phase. For comparative purposes, we present the data from this test and from a previous baseline test performed under similar conditions, with the exception that the aqueous phase was actual Tank $49 \mathrm{H}$ material. See Table 4 for the results of both tests. The tabulated results are all temperature corrected (to $23{ }^{\circ} \mathrm{C}$ for extraction and scrub steps, and to $33{ }^{\circ} \mathrm{C}$ for strip steps).

Table 4. Cesium Distribution Values for the ESS Test

\begin{tabular}{|c|c|c|c|c|c|c|}
\hline Material & Extraction & Scrub \#1 & Scrub \#2 & Strip \#1 & Strip \#2 & Strip \#3 \\
\hline Acceptable Range $^{9}$ & $>60$ & $2-4$ & $1-2.5$ & $<0.33$ & $<0.007$ & $<0.003$ \\
\hline $\begin{array}{c}\text { NGS solvent, this } \\
\text { batch }\end{array}$ & 104 & 5.79 & 2.70 & 0.00283 & $<0.00350$ & $<0.0284$ \\
\hline $\begin{array}{c}\text { NGS solvent, } \\
\text { previous test }\end{array}{ }^{10}$ & 80.6 & 3.63 & 1.13 & 0.00947 & 0.00235 & 0.337 \\
\hline
\end{tabular}

Both tests show excellent extraction results compared to what is currently used as the acceptable range of results, and both show the same trends. Scrub $\# 1 \mathrm{D}_{\mathrm{Cs}}$ results are high, as is typical with the NGS results. ${ }^{11,12,13}$ Strip \#1 and \#2 values are also quite good and within the acceptable range. In numerous experiments - both at SRNL and ORNL -Strip \#3 distribution values have shown modest increases over Strip \#2 values. In this data set, the trend is indeterminate due to the relatively high detection limits. 
High distribution values in the extraction steps are important as they indicate transference of Cs from the aqueous phase into the organic phase. Low values are important in the strip steps as they indicate successful removal of the cesium. The scrub values should show moderate values indicating not much transfer in either direction.

SRNL measured the $\mathrm{pH}$ of the aqueous phase of each scrub and strip step. The results are listed in Table 5.

Table 5. Aqueous Phase pH Results From the ESS Test

\begin{tabular}{|c|c|c|c|c|c|}
\hline Material & Scrub \#1 & Scrub \#2 & Strip \#1 & Strip \#2 & Strip \#3 \\
\hline $\begin{array}{c}\text { NGS solvent, this } \\
\text { batch }\end{array}$ & 13 & 13 & 8 & 6 & 5.5 \\
\hline
\end{tabular}

The $\mathrm{pH}$ results have a $0.5 \mathrm{pH}$ unit uncertainty and are typical of the NGS ESS tests.

\subsection{Conclusions}

Analysis of the Parsons NGS solvent indicates that the material is acceptable for use. SRNL is continuing to improve the analytical method for the guanidine. 


\subsection{References}

${ }^{1}$ S. D. Langston to K. B. Burnau, "Transfer of Next Generation Solvent (NGS) to Parsons: Contract Modification 141,” WDPD-11-86, September 30, 2011. The contract letter indicated 200 gallons of solvent but subsequent guidance from DOE representatives revised to indicate 150 gallons of mixed solvent with the remaining individual components to be shipped as received from the vendor.

${ }^{2}$ M. L. Restivo, “Next Generation Solvent Extraction, Scrub and Strip Testing”, SRNL-NB-2011-00059, May 6, 2011.

${ }^{3}$ T. B. Peters, “Next Generation Solvent Preparation”, ITS-0173, July 22, 2011.

${ }^{4}$ J. F. Birdwell and D. L. Lee, "Property Determinations and Preliminary Engineering Evaluation of Next Generation CSSX Processing.” ORNL-LTR-NGCSSX-004, 30 December 2010.

${ }^{5}$ L. H. Delmau and B. A. Moyer, "Solvent Blending Strategy to Upgrdae MCU CSSX Solvent to Equivalent Next-Generation CSSX Solvent,” ORNL-LTR-NGCSSX-010, 22 July 2011.

${ }^{6}$ N.C. Duncan, P. Bonneson, "Method Development for the Gas Chromatography (GC) Analysis of 1,3Dicyclohexyl-2-(isotridecyl)guanidine (DCITG, Suppressor for Next Generation CSSX Process Solvent, ORNL-LTR-NGCSSX-011, April 2011.

${ }^{7}$ T. B. Peters and S. D. Fink, "Results from Monosodium Titanate (MST) and Extraction-Scrub-Strip (ESS) Testing of ISDP Macrobatch 3 Blend”, SRNL-STI-2010-00290, May 2010.

${ }^{8}$ T. B. Peters, C. A. Nash, and S. D. Fink, “ISDP Salt Batch \#2 Supernate Qualification”, SRNL-STI-200800446, Rev. 1, January 5, 2009.

${ }^{9}$ B. A. Moyer, N. J. Williams, "Temperature Dependence of the Next Generation Caustic Side Solvent Extraction (NG-CSSX) Process Solvent”, ORNL-LTR-NGCSSX-012, August 5, 2011.

${ }^{10}$ T. B. Peters, A. L. Washington II, S. D. Fink, "Results of the Extraction-Scrub-Strip Testing Using an Improved Solvent Formulation and Salt Waste Processing Facility Simulated Waste”, SRNL-STI-201100689, January 2012.

${ }^{11}$ T. B. Peters and S. D. Fink, "Results of First Extraction-Scrub-Strip Testing using Improved Solvent Formulations and Actual Savannah River Site Waste”, SRNL-STI-2010-00586, September 2010.

${ }^{12}$ T. B. Peters and S. D. Fink, "Results of the Third Extraction-Scrub-Strip Real Waste Test Using An improved Solvent Formulation”, SRNL-STI-2010-00803, March 2011.

${ }^{13}$ T. B. Peters, A. L. Washington II and S. D. Fink, "Results of Cesium Mass Transfer Testing for Next Generation Solvent with Hanford Waste Simulant AP-101”, SRNL-STI-2011-00559, September 2011. 


\section{Distribution:}

E. J. Freed, 704-56H

D. J. Martin, 241-152H

M. W. Geeting, 241-152H

B. A. Gifford, 704-56H

S. P. McLeskey, 704-27S

K. L. Lang, 241-152H

B. A. Oard, 241-197H

R. E. Edwards, Jr., 773-67A

K. D. Harp, 766-H

S. G. Campbell, 999-1W

S. L. Marra, 773-A

A. B. Barnes, 773-A

C. C. Herman, 99-W

B. J. Giddings, 786-5A

F. M. Pennebaker, 773-42A

T.B. Peters, 773-42A

C. A. Nash, 773-42A

M. R. Poirier, 773-42A

F. F. Fondeur, 773-A

R. A. Pierce, 773-A

R. K. Leugemors, 992-5W

W. B. Brasel, 992-2W

C. Conner, Parsons

R. Lentsch, Parsons

P.C. Suggs, 704-S

P. R. Jackson, 703-46A 